\title{
ANALISIS KINERJA SIMPANG STEGER TAK BERSINYAL PADA JL. BUAH BATU - JL. SOLONTONGAN - JL. SURYALAYA KOTA BANDUNG
}

\author{
Defari Jananuraga ${ }^{1}$, Tan Lie Ing ${ }^{2}$ \\ ${ }^{1}$ Alumnus Jurusan Teknik Sipil Fakultas Teknik Universitas Kristen Maranatha \\ Jl. Prof. drg. Suria Sumantri, MPH., No. 65, Bandung, 40164 \\ E-mail : aerotus_def@yahoo.co.uk \\ ${ }^{2}$ Dosen Tetap Jurusan Teknik Sipil Fakultas Teknik Universitas Kristen Maranatha \\ Jl. Prof. drg. Suria Sumantri, MPH., No. 65, Bandung, 40164 \\ E-mail : lieing.tan@yahoo.com
}

\begin{abstract}
ABSTRAK
Kota Bandung merupakan kota yang banyak memiliki simpang dan jarak antara simpangnya berdekatan. Simpang merupakan pertemuan antara beberapa jalan menjadi satu. Pada simpang sering terjadi konflik kendaraan bermotor, khususnya simpang tidak bersinyal. Kecenderungan pengguna kendaraan bermotor pada saat ini selalu ingin cepat dan ingin menang sendiri dan sering mengakibatkan konflik di persimpangan. Akibat terjadinya konflik dan hambatan pada persimpangan, maka meningkatnya juga tundaan dan derajat kejenuhan (DS) di simpang tersebut. Analisis dilakukan pada simpang empat steger tak bersinyal, tepatnya pada jl.Buahbatujl.Solontongan-j1.Suryalaya. Data diperoleh dari survei lapangan berupa geometri simpang, arus lalulintas pada waktu pagi, siang dan sore selama 3 jam kemudian diambil peakhour, pola pergerakan kendaraan pada jam tertentu, kecepatan dan keadaan hambatan samping secara visual pada simpang tersebut. Analisis terhadap simpang empat steger tak bersinyal ini dilakukan dengan mengunakan metode MKJI yaitu simpang empat bersinyal, Simpang tiga tak bersinyal dan simpang tiga bersinyal. Analisis awal dilakukan dengan menggunakan metode MKJI simpang tiga tak bersinyal untuk mengetahui kinerja simpang tersebut dan menghasilkan DS $>1$. Alternatif yang dianalisis sebanyak 3 alternatif dan menghasilkan data tundaan dan derajat kejenuhan. Dari ketiga alternatif tersebut didapatkan Alternatif terpilih yaitu alternatif 3 dengan cara menggunakan separator pada area disekitar simpang tersebut sepanjang $300 \mathrm{~m}$ dan menghasilkan derajat kejenuhan rata-rata $<0,6$.
\end{abstract}

Kata kunci : Tundaan, Derajat Kejenuhan (DS), Peakhour, Hambatan samping, Simpang tiga tak bersinyal.

\section{PENDAHULUAN}

\subsection{Latar Belakang}

Seiring berkembangnya kota dan tingginya populasi penduduk berdampak meningkatnya aktivitas perkotaan yang menimbulkan kemacetan lalulintas. Kemacetan lalulintas yang terjadi di kota Bandung diakibatkan oleh banyak faktor. Faktor yang paling mendominasi yaitu tingginya pertumbuhan kendaraan bermotor baik roda 2 ataupun roda 4 yang tak sebanding dengan pertumbuhan kapasitas jalan yang ada di kota Bandung. Kesadaran para pengguna jalan terhadap tata tertib pun ikut serta menimbulkan kemacetan dan meningkatnya tingkat kecelakaan. Banyak kerugian yang timbul diakibatkan oleh kemacetan, yaitu pembakaran tidak sempurna yang dihasilkan kendaraan bermotor, banyaknya waktu, yang terbuang, meningkatnya kebisingan, 
konsumsi bahan bakar yang terbuang percuma, itu semua berdampak tidak baik bagi penduduk yang ada disekitarnya.

Untuk mengatasi kepadatan lalulintas tersebut, tidak sekedar membuka jalan baru, tetapi perlu ada perbaikan dalam sistem manajemen lalulintas, pembenahan hambatan samping atau pemasangan lampu lalulintas. Sistem manajemen yang ada masih belum tertata dengan baik, terutama pada simpang tidak bersinyal yang sering kali timbul kemacetan lalu lintas.

Simpang empat steger yang berada di jalan Buahbatu sering kali menimbulkan kemacetan. Simpang tersebut dulu memiliki lampu persinyalan, akan tetapi saat ini lampu persinyalan tersebut tidak dinyalakan atau sudah tidak beroperasi lagi dikarenakan berbagai banyak hal. Simpang tersebut mempunyai 2 lengan yang tidak sejajar, yaitu pada lengan yang menuju jalan Solontongan dan Jalan Suryalaya. Jalan Buahbatu sering kali terjadi kemacetan dikarenakan daerah tersebut termasuk daerah komersil ,pemukiman penduduk dan daerah pendidikan. Di sekitar daerah jalan Buahbatu terdapat banyak pusat perbelanjaan, toko, Universitas dan sekolah diantaranya SMUN 8, SMPN 28, SMKN 3, dan tempat bimbingan belajar. Yang dapat menimbulkan kemacetan dikarenakan banyaknya siswa sekolah yang menyebrang, berhentinya angkutan umum, keluar masuknya kendaraan dari tempat perbelanjaan dan simpang 4 steger yang tak bersinyal yang mempunyai volume kendaraan yang cukup besar.

\subsection{Tujuan}

Tujuan dari penelitian ini adalah mengevaluasi kinerja simpang steger tersebut kemudian memberikan alternatif solusi untuk peningkatan kinerja simpang tersebut.

\subsection{Ruang Lingkup}

1. Simpang empat steger tak bersinyal pada Jl. Buahbatu - Jl. Suryalaya - Jl. Solontongan kota Bandung

2. Menganalisis kinerja simpang menggunakan MKJI 1997.

3. Aspek lalu lintas yang ditinjau hanya dari pola pergerakan lalu lintas kendaraan, arus kendaraan dan konflik di area persimpangan Jl. Buahbatu - Jl.Suryalaya Jl.Solontongan kota Bandung

4. Pembenahan hambatan samping dan fasilitas di area persimpangan Jl.Buahbatu - J1.Suryalaya - J1.Solontongan kota Bandung.

5. Survei kendaraan sesuai dengan pola pergerakan yang ada karena ada pergerakan yang tidak diperbolehkan di simpang tersebut. 
6. Survei dilakukan selama 3 jam, pada waktu 06:00 - 09:00 Pagi, 11:00 - 14:00 Siang dan 15:00 - 18:00 Sore pada hari Senin dan Kamis.

\section{TINJAUAN PUSTAKA}

\subsection{Teori Arus dan Klasifikasi Jalan}

Arus lalulintas adalah jumlah kendaraan yang terdapat dalam ruang yang diukur dalam satu interval waktu tertentu. Ukuran dasar dari arus lalulintas yang sering digunakan adalah konsentrasi aliran dan kecepatan. Konsentrasi aliran dianggap sebagai jumlah kendaraan pada suatu panjang jalan, sedangkan kecepatan ditentukan dari jarak yang ditempuh oleh kendaraan pada satuan waktu atau dalam beberapa penelitian ratarata kecepatan dihitung terhadap distribusi waktu kecepatan (kecepatan waktu rata-rata) atau kecepatan distribusi ruang (kecepatan ruang rata-rata).

Arus lalulintas (Q) untuk setiap gerakan (belok dan lurus) dikonversi dari kendaraan perjam menjadi satuan mobil penumpang (smp) perjam dengan menggunakan ekivalen kendaraan penumpang (emp) untuk masing-masing pendekat terlindung dan terlawan. Kendaraan dikelompokan menjadi beberapa bagian seperti diperlihatkan oleh Tabel 1.

Tabel 1. Kelompok Kendaraan.

\begin{tabular}{|c|c|c|}
\hline No & Tipe Kendaraan & Definisi \\
\hline 1 & Kendaraan tak bermotor (UM) & Sepeda, becak \\
\hline 2 & Sepeda bermotor (MC) & Sepeda motor \\
\hline 3 & Kendaraan ringan (LV) & Colt, pick up, station wagon \\
\hline 4 & Kendaraan berat (HV) & Bus, truck \\
\hline
\end{tabular}

Klasifikasi jalan dalam peraturan perencanaan geometri jalan raya (PPGJR) oleh Dirjen Bina Marga 1970 menurut fungsinya, jalan diklasifikasikan menjadi 3 golongan antara lain:

1. Jalan utama yaitu jalan yang melayani lalulintas yang tinggi antara kota-kota yang penting atau antara pusat-pusat produksi dan pusat-pusat ekspor. Jalan dalam golongan ini direncanakan untuk dapat melayani lalulintas yang cepat dan berat. Jalan utama mempunyai kelas I dengan lalulintas harian rata-rata (LHR dalam smp) lebih dari 20000.

2. Jalan sekunder yaitu jalan yang melayani lalulintas yang cukup tinggi antar kota-kota penting dan kota yang lebih kecil serta melayani daerah sekitarnya. Jalan sekunder 
mempunyai kelas IIA (LHR 6000 - 20000 smp), IIB (LHR 1500 - 8000 smp), dan IIC (LHR lebih kecil dari $2000 \mathrm{smp}$ )

3. Jalan penghubung yaitu jalan untuk keperluan aktivitas daerah yang juga dipakai sebagai jalan penghubung antara jalan-jalan dari golongan yang sama maupun berlainan, jalan ini mempunyai kelas III.

\subsection{Persimpangan}

Berdasarkan MKJI 1997, persimpangan merupakan pertemuan dua jalan atau lebih yang bersilangan. Secara umum simpang terdiri dari simpang bersinyal dan simpang tak bersinyal. Persimpangan steger yaitu persimpangan dimana satu kakinya bergeser atau persimpangan tegak lurus yang salah satunya bergeser (tidak menerus bersilang). Jarak dari kedua kaki simpang biasanya berkisar $30 \mathrm{~m}-100 \mathrm{~m}$ dari as jalan.

\subsection{Simpang Tak Bersinyal}

a. Lebar Rata-Rata Pendekat

Pendekat merupakan daerah lengan persimpangan jalan untuk kendaraan mengantri sebelum keluar melewati garis henti. Lebar pendekat diukur pada jarak $10 \mathrm{~m}$ dari garis imajiner yang menghubungkan tipe perkerasan dari jalan berpotongan, yang dianggap mewakili lebar pendekat efektif untuk masing-masing pendekat.

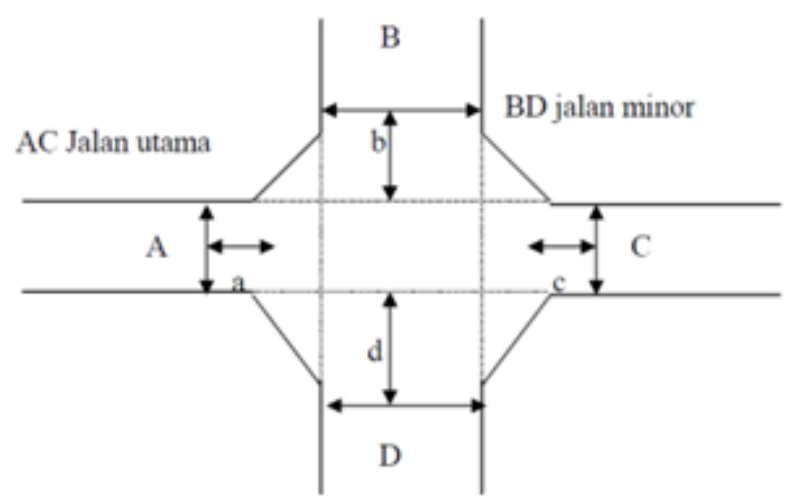

Gambar 1. Lebar Rata-Rata Pendekat.

b. Tipe Simpang (IT) Berdasarkan Jumlah Lengan Simpang

Tipe simpang diklasifikasikan berdasarkan jumlah lengan, jumlah lajur jalan mayor dan minor.

c. Kapasitas

Kapasitas persimpangan secara menyeluruh dapat diperoleh dengan menggunakan 


\section{$c=C_{0} \times E_{W} \times F M \times F_{g g} \times F_{R S U} \times F L T \times F R T \times F M I\left({ }^{o m p} / f a m\right)$}

Kapasitas dasar merupakan kapasitas persimpangan jalan total untuk suatu kondisi tertentu yang telah ditentukan sebelumnya (kondisi dasar). Kapasitas dasar (smp/jam) ditentukan oleh tipe simpang.

\section{d. Faktor Penyesuaian Lebar Pendekat}

Faktor penyesuaian lebar pendekat $(\mathrm{Fw})$ ini merupakan faktor penyesuaian untuk kapasitas dasar sehubungan dengan lebar masuk persimpangan jalan.

e. Faktor Penyesuaian Median Jalan Utama (FM)

FM ini merupakan faktor penyesuaian untuk kapasitas dasar sehubungan dengan tipe median jalan utama. Tipe median jalan utama merupakan klasifikasi media jalan utama, tergantung pada kemungkinan menggunakan media tersebut untuk menyeberangi jalan utama dalam dua tahap.

\section{f. Faktor Penyesuaian Ukuran Kota $\left(\mathrm{F}_{\mathrm{cs}}\right)$}

Faktor ini hanya dipengaruhi oleh variabel besar kecilnya jumlah penduduk dalam juta.

g. Faktor Penyesuaian Tipe Lingkungan, Kelas Hambatan Samping dan Kendaraan Tak Bermotor $\left(\mathrm{F}_{\mathrm{RSU}}\right)$

Faktor penyesuaian tipe lingkungan jalan, hambatan samping dan kendaraan tak bermotor $\left(\mathrm{F}_{\mathrm{RSU}}\right)$, dengan variabel masukkan adalah tipe lingkungan jalan (RE), kelas hambatan samping (SF) dan rasio kendaraan tak bermotor UM/MV.

h. Faktor penyesuaian belok kiri (FLT)

Persamaan yang digunakan dalam pencarian faktor penyesuaian belok kiri.

$$
F E T=0,84+1,61 P L T
$$

i. Faktor penyesuaian belok kanan (FRT)

Faktor penyesuaian belok kanan untuk simpang jalan dengan empat lengan adalah FRT $=$ 1.0, Untuk simpang 3 - lengan, variabel masukan adalah belok kanan PRT. FRT $=1,09-$ 0,922 PRT. 
j. Faktor Penyesuaian rasio arus minor (FMI)

Pada faktor ini yang banyak mempengaruhi adalah rasio arus pada jalan (PMI) dan tipe simpang (IT) pada persimpangan jalan tersebut.

k. Derajat Kejenuhan (DS)

Derajat kejenuhan merupakan rasio lalulintas terhadap kapasitas. Jika yang diukur adalah kejenuhan suatu simpang maka derajat kejenuhan disini merupakan perbandingan dari total arus lalulintas (smp/jam) terhadap besarnya kapasitas pada suatu persimpangan (smp/jam).

$$
D S=\frac{Q T O T}{C}
$$

1. Tundaan Lalulintas Simpang (DT1)

Tundaan lalulintas simpang adalah tundaan lalulintas rata-rata untuk semua kendaraan bermotor yang masuk simpang. DT1 ditentukan dari kurva empiris antara DT1 dan DS1 dengan rumus:

untuk DS $\leq 0,6$

$$
B z^{*}=2+8,2078 \times D S-(1-B S) \times 2
$$

untuk DS $\geq 0,6$

$$
D T=\frac{1,0504}{(0,274.2-0,204.2 \times D S)-(1-D S) \times 2}
$$

m. Tundaan Lalulintas Jalan Utama (DTMA)

Tundaan lalulintas jalan utama adalah tundaan lalulintas rata-rata semua kendaraan bermotor yang masuk persimpangan dari jalan utama.

untuk DS $\leq 0,6$

$$
D T M A=1,8+5,8234 \times D S-(1-D S) \times 1,8
$$

untuk DS $\geq 0$

$$
D T M A=\frac{1,05034}{(0,346-0,24 \times D S)-(1-D S) \times 1,8}
$$

m. Penentuan Tundaan Lalulintas Jalan Minor (DTMI)

Tundaan lalulintas jalan minor rata-rata ditentukan berdasarkan tundaan simpang rata-rata dan tundan jalan utama rata-rata. 


$$
D T M I=\frac{(Q T O T \times D T 1)-(Q M A \times D T M A)}{Q M I}
$$

n. Tundaan Geometri Simpang (DG)

Tundan geometri simpang adalah tundaan geometri rata-rata seluruh kendaraan bermotor masuk simpang.

untuk DS $<1,0$

$$
D S=(1-D S) \times(P T \times 6+(1-P T) \times 3)+D S \times 4
$$

untuk DS $\geq 1,0: \mathrm{DG}=4$

o. Tundaan Simpang (D)

Tundaan Simpang yaitu tundaan yang diakibatkan oleh simpang.

$$
D=D G+D T 1(\operatorname{det} / \operatorname{smp})
$$

p. Peluang Antrian (QP)

Untuk menghitung peluang antrian dapat dilihat dengan menggunakan persamaan:

Batas bawah:

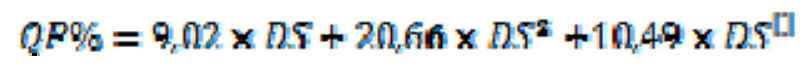

Batas atas:

$$
Q P \%=47,71 \times D S-24,68 \times D S^{2}-56,47 \times D S^{3}
$$

\subsection{Simpang Bersinyal}

Sinyal lalulintas adalah alat yang berfungsi untuk mengatur saat pergerakan dan lama waktu berjalan dari kendaraan di kaki simpang. Fungsi utama dari persinyalan yaitu menghindari arah pergerakan kendaraan yang saling berpotongan atau melalui titik konflik pada saat yang sama.

Ada dua konflik pada simpang yaitu konflik primer dan konflik sekunder. Sinyal lampu lalulintas akan dapat menghilangkan konflik primer bahkan mungkin juga konflik sekunder. Hal ini tergantung dari karakter simpang. Pada prinsipnya, simpang yang tidak memiliki konflik (protected) maka tidak akan ada aliran pergerakan yang terganggu, akan tetapi jika masih ada aliran pergerakan yang terganggu, maka disebut dengan terganggu (permitted). Berdasarkan MKJI 1997 kinerja operasi suatu simpang diukur dari kapasitas, derajat kejenuhan, panjang antrian, rasio kendaraan terhenti dan tundaan. 


\section{a. Data Geometri dan Lalulintas}

Kondisi geometri simpang digambarkan dalam bentuk sketsa dengan tujuan memberikan informasi lebar masuk dan lebar keluar simpang, lebar pendekat, jumlah lajur pada masing-masing lengan, median serta penunjuk arah untuk setiap lengan. Data lalulintas menurut MKJI 1997 dibagi kedalam empat tipe kendaraan, diantaranya kendaraan ringan (LV), kendaraan berat (HV), sepeda motor (MC), dan kendaraan tak bermotor (UM).

$$
Q=\left(Q_{L W} \times m p_{L W}\right)+\left(Q_{H V} \times \oplus m p_{L V}\right)+\left(Q_{M C} \times \oplus m p_{M C}\right)
$$

b. Arus Jenuh

Arus jenuh merupakan besarnya keberangkatan antrian didalam suatu lengan simpang selama kondisi yang ditentukan (smp/jam hijau). Arus jenuh (S) dapat dinyatakan sebagai hasil perkalian dari arus jenuh dasar (So) yaitu arus jenuh pada keadaan standar, dengan faktor penyesuaian (F) untuk penyimpangan dari kondisi sebenarnya, dari suatu kumpulan kondisi-kondisi (ideal) yang telah ditetapkan sebelumnya.$$
s=s_{Q} \times F_{G S} \times F_{S F} \times F_{Q} \times F_{D} \times F_{R T} \times F_{L F}
$$

\section{c. Lebar Efektif}

i. Jika $\mathrm{W}_{\text {LTOR }} \geq 2 \mathrm{~m}$

We dihitung dari nilai terkecil antara: $\mathrm{Wa}-\mathrm{W}_{\mathrm{LTOR}}$ dan $\mathrm{W}_{\text {MASUK }}$

Jika $\mathrm{W}_{\text {KELUAR }}<\mathrm{We} \times \quad\left(1-\mathrm{P}_{\mathrm{RT}}\right)$, We sebaiknya diberi nilai baru sama dengan $\mathrm{W}_{\text {KELUAR }}$ serta penentuan waktu sinyal untuk pendekat ini dilakukan hanya untuk bagian lalulintas lurus saja.

ii. Jika kondisi $\mathrm{W}_{\mathrm{LTOR}}<2 \mathrm{~m}$

We dihitung dari nilai terkecil antara:

$\mathrm{Wa}, \mathrm{W}_{\text {MASUK }}+\mathrm{W}_{\mathrm{LTOR}}$ dan $\mathrm{Wa} \times\left(1+\mathrm{P}_{\mathrm{LTOR}}\right)-\mathrm{W}_{\mathrm{LTOR}}$

Jika WKELUAR < We $\mathbf{x}$ (1 - PRT - PLTOR) We sebaiknya diberi nilai baru sama dengan $\mathrm{W}_{\text {KELUAR }}$ serta penentuan waktu sinyal untuk pendekat ini dilakukan hanya untuk bagian lalulintas lurus saja.

\section{d. Rasio Arus}

Perhitungan rasio arus (Q) dengan arus jenuh (S) untuk tiap pendekat.

$$
F R=\frac{Q}{S}
$$




$$
\begin{aligned}
& I F R=\sum\left(F R_{\text {ont }}\right) \\
& P R=\frac{F R_{\text {ort }}}{I F R}
\end{aligned}
$$

e. Waktu Siklus dan Waktu Hijau

Waktu siklus untuk fase merupakan waktu siklus optimum dengan tundaan yang dihasilkan adalah kecil. Waktu hijau yang lebih pendek dari 10 detik harus dihindari, karena dapat mengakibatkan pelanggaran lampu merah yang berlebihan dan kesulitan bagi pejalan kaki untuk menyeberang jalan

$$
\begin{aligned}
& \varepsilon=\frac{(1,5 \times E T 1+5)}{\left(1-\Sigma s R_{\text {omt }}\right)} \\
& E T=\sum(\text { ali red }+ \text { mber })_{l}=\sum I G_{i} \\
& \theta_{t}=(T-t . T 1) \times P R
\end{aligned}
$$

\section{f. Kapasitas}

Kapasitas merupakan arus lalulintas maksimum yang dapat dipertahankan pada suatu bagian jalan dengan melihat kondisi geometrik jalan, lingkungan dan komposisi lalulintas tertentu.

$$
C=S \times \frac{\theta}{\epsilon}
$$

h. Panjang Antrian

Panjang antrian merupakan panjang kendaraan yang mengantri atau terhenti dikarenakan pengaturan sinyal lalulintas. Dari nilai derajat kejenuhan dapat diketahui jumlah antrian smp (NQ1) yang merupakan sisa dari fase hijau sebelumnya dan jumlah smp yang datang pada selama fase merah (NQ2).

Untuk $\mathrm{DS}>0,5$, perhitungan $\mathrm{NQ}_{1}$ menggunakan persamaan:

$$
N Q_{1}=0,25 \times C \times\left[(D S-1)+\sqrt{(D S-1)^{2}+\frac{8 \times(D S-0,5)}{C}}\right]
$$

Untuk Ds $\leq 0,5$, maka nilai $\mathrm{NQ}_{1}=0$

$$
N Q_{2}=\epsilon \times \frac{1-G R}{1-G R \times D S} \times \frac{Q}{3600}
$$




$$
\begin{aligned}
& N Q=N Q_{1}+N Q_{2} \\
& Q L=\frac{N Q_{\text {maxx }} 20}{W_{\text {MASUR }}}
\end{aligned}
$$

\section{i. Tundaan}

Tundaan adalah waktu tambahan yang diperlukan kendaraan ketika melewati simpang dibandingkan dengan situasi tanpa melewati simpang. Tundaan Lalulintas (DT), yaitu tundaan yang terjadi dikarenakan interaksi lalulintas dengan gerakan lainnya pada suatu simpang. Tundaan Geometri (DG), yaitu tundaan yang terjadi dikarenakan perlambatan dan percepatan sebuah kendaraan pada saat membelok pada suatu simpang (disebabkan oleh kondisi geometri simpang) atau terhenti karena lampu merah.

$$
\begin{aligned}
& D=D T+E G \\
& D T=\epsilon x \frac{0,5 x\left(1-G R^{2}\right.}{(1-G R \times D 5)}+\frac{N Q_{1} \times 3600}{C} \\
& D G=\left(1-P_{S V}\right) \times P_{T} \times 6+\left(P_{S V} \times 4\right)
\end{aligned}
$$

\subsection{Median dan Jalur Pemisah}

Median adalah sejalur lahan yang diperuntukkan untuk memisahkan jalur lalulintas yang berlawanan arah, penempatan perlengkapan jalan, tanaman perdu yang berakar tunggang, sebagai fungsi estetika dan meredam sinar lampu kendaraan dari arah yang berlawanan. Jalur pemisah adalah sejalur lahan yang diperuntukkan untuk memisahkan jalur lalulintas yang searah. Kalau memungkinkan peruntukkannya sama dengan median. Tabel 2.14 diambil dari Tabel 3-PD7-17-2004B.

Tabel 2. Jarak Bukaan dan Jarak Antar Bukaan.

\begin{tabular}{|c|c|c|c|c|c|}
\hline \multirow{2}{*}{$\begin{array}{c}\text { Fungsi } \\
\text { Jalan }\end{array}$} & \multicolumn{2}{|c|}{ Luar Kota } & \multicolumn{3}{|c|}{ Perkotaan } \\
\cline { 2 - 5 } & $\begin{array}{c}\text { Jarak } \\
\text { Bukaan } \\
\left(\mathrm{d}_{1}, \mathrm{~km}\right)\end{array}$ & $\begin{array}{c}\text { Lebar } \\
\text { Bukaan } \\
\left(\mathrm{d}_{2}, \mathrm{~m}\right)\end{array}$ & \multicolumn{2}{|c|}{$\begin{array}{c}\text { Jarak Bukaan } \\
\left(\mathrm{d}_{1}, \mathrm{~km}\right)\end{array}$} & $\begin{array}{c}\text { Lebar } \\
\text { Bukaan } \\
\left(\mathrm{d}_{2}, \mathrm{~km}\right)\end{array}$ \\
\cline { 5 - 6 } & & 7 & Pinggir Kota & Dalam Kota & \\
\hline Arteri & 5 & 2,5 & 0,5 & 4 \\
\hline Kolektor & 3 & 4 & 1,0 & 0,3 & 4 \\
\hline
\end{tabular}

\section{METODE PENELITIAN}

Penelitian dilakukan pada dua simpang tiga tak bersinyal atau simpang empat steger tak bersinyal pada jalan Buahbatu. Berdasarkan survey pendahuluan, waktu survei 
ditentukan yaitu pagi hari 06:00 - 09:00, siang hari 11:00 - 13:00 dan sore hari 15:00 16:00 pada hari senin dan kamis. Dari data pengambilan volume kendaraan tersebut, di dapat waktu sibuk optimum selama satu jam pada pagi,siang dan sore. Data tersebut dipergunakan untuk evaluasi kinerja simpang dan perencanaan alternatif solusi. Perencanaan alternatif solusi menggunakan MKJI 1997 simpang bersinyal dan simpang tak bersinyal.

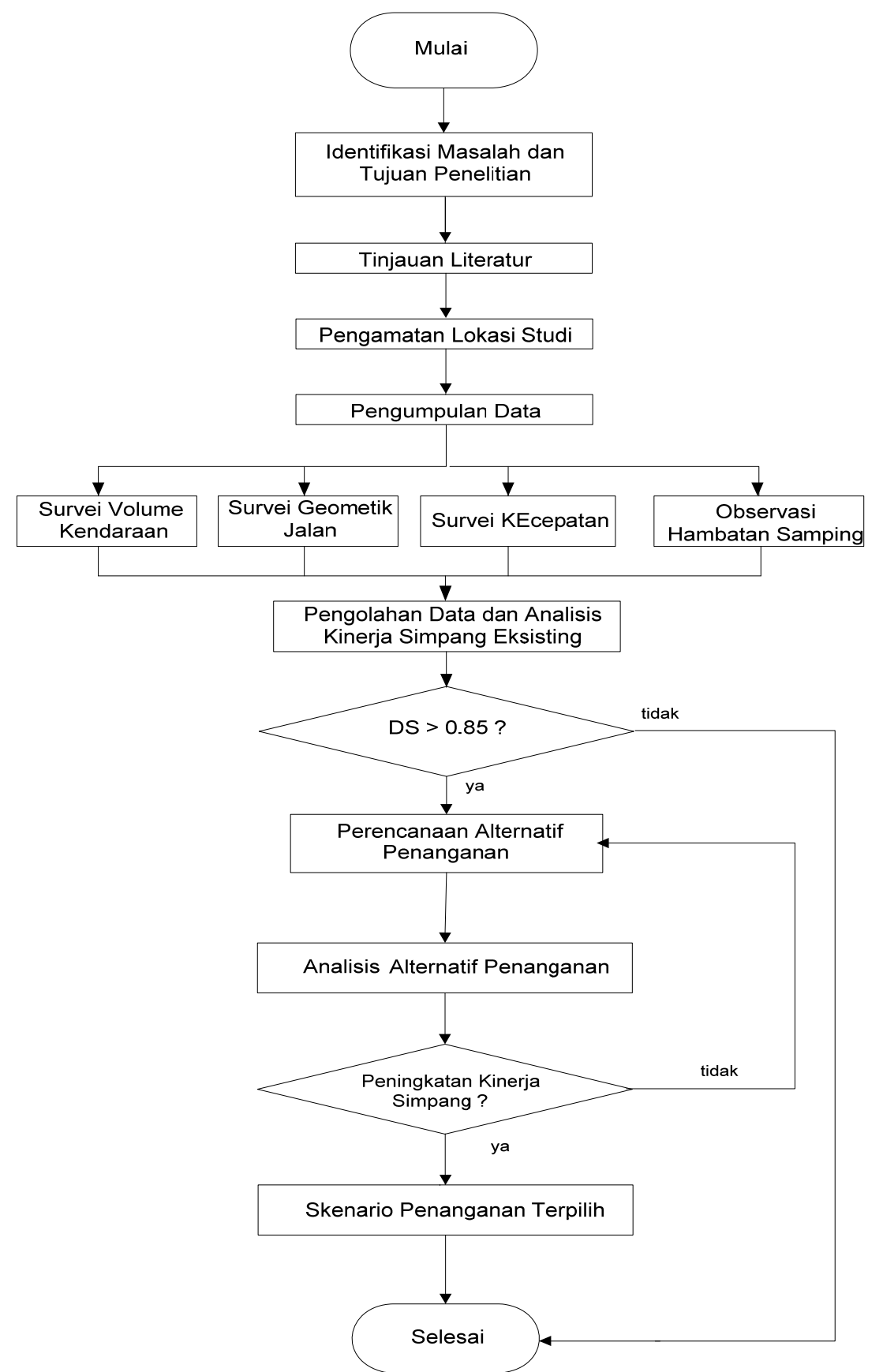

Gambar 2. Bagan Alir Penelitian. 


\section{ANALISIS DATA DAN PEMBAHASAN}

Kondisi persimpangan di area jalan Buah batu memiliki jarak yang berdekatan. Khususnya simpang pada jalan Solontongan (Simpang 1) dan jalan Suryalaya (Simpang 2) yang memiliki Simpang 3 tidak bersinyal. Analisis yang dilakukan sangat berkaitan antara Simpang 1 dan Simpang 2.

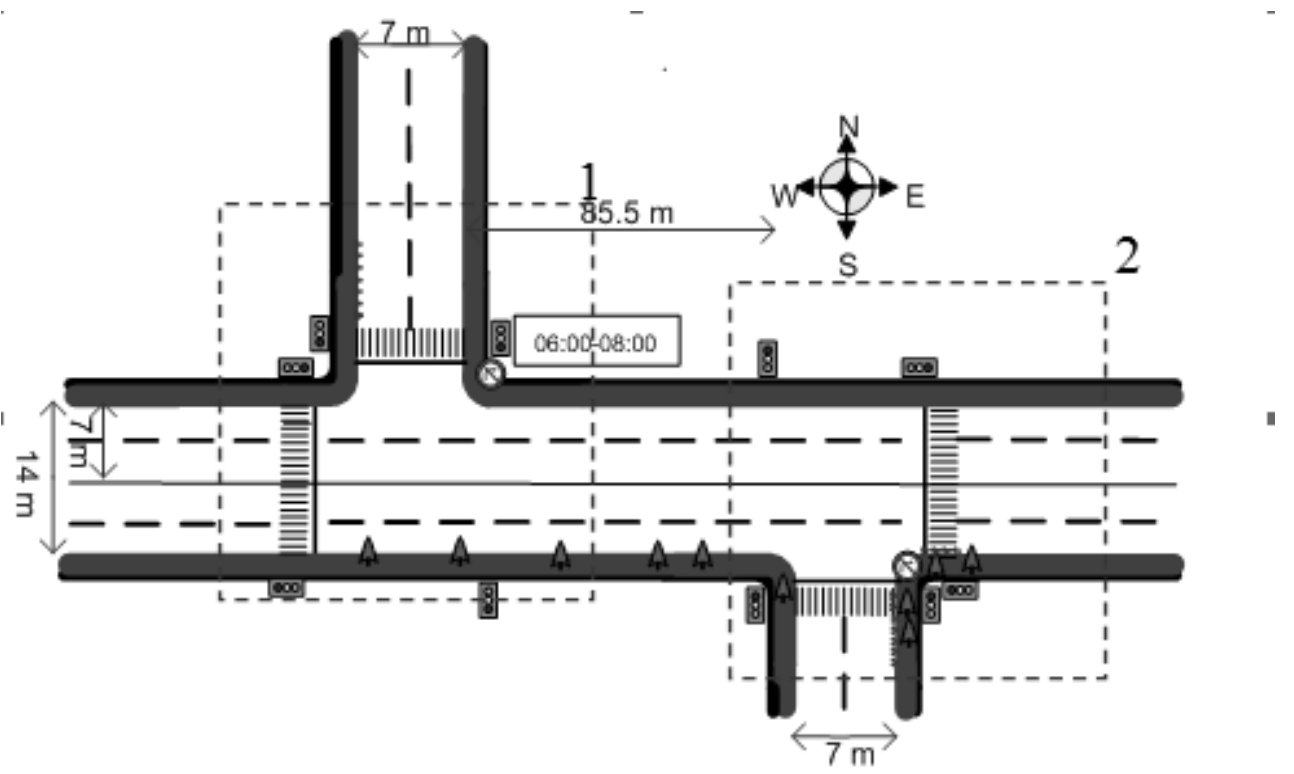

Gambar 3. Kondisi Geometrik Simpang.

\subsection{Kondisi Geometri}

a. Simpang 1

Simpang 1 merupakan simpang tiga tak bersinyal yang terletak di kawasan komersial yang dikelilingi pertokoan dan tempat pendidikan. Simpang 1 merupakan pertemuan antara ruas Jalan Buahbatu dan Jalan Solontongan.

Tabel 3. Karakteristik Simpang 1.

\begin{tabular}{|c|c|c|c|c|c|c|}
\hline $\begin{array}{c}\text { Lengan } \\
\text { Simpang }\end{array}$ & Nama Jalan & Peran Jalan & Tipe & $\begin{array}{c}\text { Lebar } \\
\text { Jalan } \\
(\mathrm{m})\end{array}$ & $\begin{array}{c}\text { NSPM } \\
(\mathrm{m})\end{array}$ & $\begin{array}{c}\text { Sesuai } \\
\text { Ketentuan }\end{array}$ \\
\hline D & Jl.Buahbatu & $\begin{array}{c}\text { Kolektor } \\
\text { Sekunder }\end{array}$ & $\begin{array}{c}4 / 2 \\
\text { UD }\end{array}$ & 14 & $\geq 7,0$ & $\checkmark$ \\
\hline C & Jl.Solontongan & $\begin{array}{c}\text { Lokal } \\
\text { Sekunder }\end{array}$ & $\begin{array}{c}4 / 2 \\
\text { UD }\end{array}$ & 7 & $\geq 4,0$ & $\checkmark$ \\
\hline B & Jl.Buahbatu & $\begin{array}{c}\text { Kolektor } \\
\text { Sekunder }\end{array}$ & $\begin{array}{c}4 / 2 \\
\text { UD }\end{array}$ & 14 & $\geq 7,0$ & $\checkmark$ \\
\hline
\end{tabular}




\section{b. Simpang 2}

Simpang 2 ini sama halnya dengan Simpang 1, berada di kawasan komersil dan pendidikan. Simpang 2 merupakan pertemuan antara ruas Jalan Buahbatu dan Jalan Suryalaya.

Tabel 4. Karakteristik Simpang 2.

\begin{tabular}{|c|l|c|c|c|c|c|}
\hline $\begin{array}{c}\text { Lengan } \\
\text { Simpang }\end{array}$ & Nama Jalan & $\begin{array}{c}\text { Peran } \\
\text { Jalan }\end{array}$ & Tipe & $\begin{array}{c}\text { Lebar } \\
\text { Jalan (m) }\end{array}$ & $\begin{array}{c}\text { NSPM } \\
(\mathrm{m})\end{array}$ & $\begin{array}{c}\text { Sesuai } \\
\text { Ketentuan }\end{array}$ \\
\hline D & Jl.Buahbatu & $\begin{array}{c}\text { Kolektor } \\
\text { Sekunder }\end{array}$ & $4 / 2$ UD & 14 & $\geq 7,0$ & $\checkmark$ \\
\hline C' & Jl.Suryalaya & $\begin{array}{c}\text { Lokal } \\
\text { Sekunder }\end{array}$ & $4 / 2$ UD & 7 & $\geq 4,0$ & $\checkmark$ \\
\hline B & Jl.Buahbatu & $\begin{array}{c}\text { Kolektor } \\
\text { Sekunder }\end{array}$ & $4 / 2$ UD & 14 & $\geq 7,0$ & $\checkmark$ \\
\hline
\end{tabular}

\subsection{Analisis}

Analisis yang dilakukan pada Simpang 1 dan Simpang 2 tak bersinyal ini menggunakan metoda MKJI 1997 dengan cara mendapatkan volume lalulintas yang ada di lapangan. Data tersebut kemudian di analisis untuk mendapatkan derajat kejenuhan dan tundaan pada simpang tersebut. Data arus lalulintas yang digunakan yaitu data dari hasil survey hari senin dan kamis pada waktu pagi. siang dan sore selama 3 jam pada Simpang 1 dan Simpang 2. Data tersebut kemudian dianalisis untuk mendapatkan satu jam sibuk pada waktu pagi siang dan sore. Volume kendaraan yang didapatkan pada 1 jam sibuk tersebut dikalikan dengan emp untuk masing masing kendaraan sehingga didapatkan keseragaman dalam satuan smp/jam.

Evaluasi dilakukan pada kedua simpang tersebut atau simpang steger dengan menggunakan MKJI 1997 simpang 3 tak bersinyal. Hasil dari evaluasi simpang tesebut pada waktu pagi siang dan sore pada kedua simpang menghasilkan derajat kejenuhan dan tundaan, terlihat pada Table 4.

Tabel 5. Derajat Kejenuhan dan Tundaan simpang.

\begin{tabular}{|c|c|c|c|c|}
\hline \multirow{2}{*}{ WAKTU } & \multicolumn{2}{|c|}{ Derajat Kejenuhan (DS) } & \multicolumn{2}{c|}{ Tundaan Simpang } \\
\cline { 2 - 5 } & Simpang 1 & Simpang 2 & Simpang 1 & Simpang 2 \\
\hline PAGI & 1.220 & 1.016 & 46.551 & 19.792 \\
\hline SIANG & 0.888 & 0.969 & 14.974 & 17.679 \\
\hline SORE & 0.926 & 0.994 & 16.117 & 18.751 \\
\hline
\end{tabular}




\subsection{Perancangan Alternatif Solusi dan Evaluasi Alternatif Solusi}

Perlakuan terhadap persimpangan dengan tetap memperhitungkan volume kendaraan per kapasitas jalan sebagai indikator tingkat pelayanan jalan (persimpangan) pada wilayah studi. Dengan menggunakan alternatif solusi penanganan, bahwa pertambahan arus lalulintas kendaraan yang melewati persimpangan daerah studi akan terus bertambah, sementara kapasitas persimpangan tetap. Selain itu dilakukan juga kajian dengan bobot untuk menganalisis simpang-simpang dengan menggunakan ketentuan, peraturan maupun NSPM yang berlaku. Perancangan alternatif solusi pada studi kasus ini dilakukan dengan beberapa alternatif,diantaranya:

1. Menjadikan simpang tersebut masing-masing simpang 3 bersinyal

2. Menjadikan simpang tersebut Simpang empat bersinyal dalam 1 siklus waktu.

3. Memasang median jalan sepanjang ruas jalan tersebut.

\subsection{Evaluasi Alternatif Solusi}

Hasil dari analisis ke 3 alternatif solusi tersebut didapatkan alternatif solusi terpilih dengan analisis menggunakan metoda MKJI 1997 simpang 3 tak bersinyal dan simpang 4 bersinyal. Dari analisis tersebut terpilihlah alternatif solusi yaitu alternatif ke tiga dengan memasang median sepanjang $300 \mathrm{~m}$ dengan bukaan simpang $4 \mathrm{~m}$. alternatif ke tiga menghasilkan derajat kejenuhan dan tundaan simpang yang paling rendah dibandingkan kedua alternative lainnya. Hasil dari analisis alternatif ke tiga dapat terlihat pada Tabel 6 dan Gambar 4.

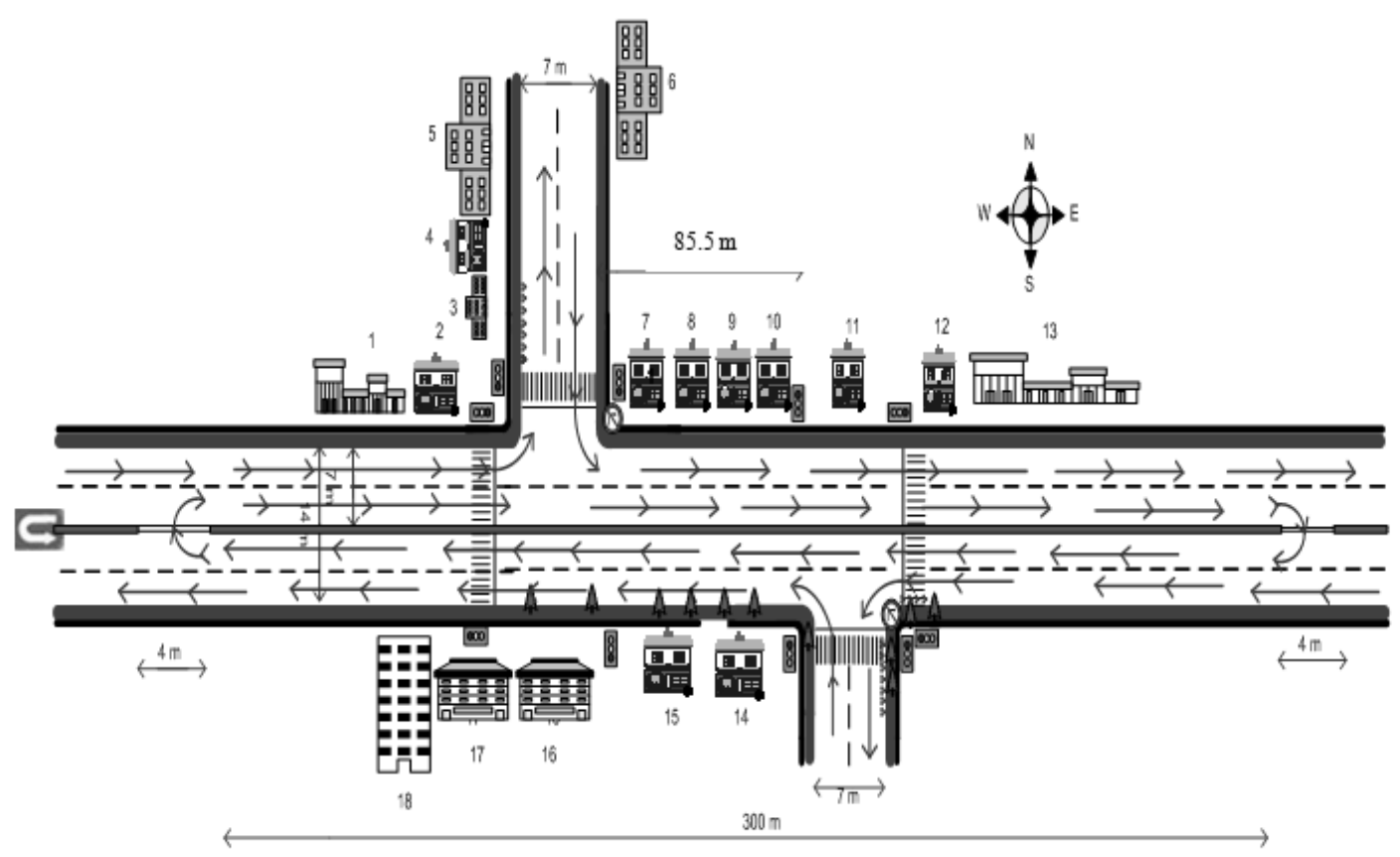

Gambar 4. Kondisi Geometri Setelah Menggunakan Median. 
Tabel 6. Derajat Kejenuhan (DS) dan Tundaan Simpang.

\begin{tabular}{|c|c|c|c|c|c|c|c|c|}
\hline \multirow{3}{*}{ Waktu } & \multicolumn{3}{|c|}{ Drajat Kejenuhan (DS) } & \multicolumn{4}{c|}{ Tundaan Simpang } \\
\cline { 2 - 9 } & \multicolumn{2}{|c|}{ Kondisi Awal } & \multicolumn{2}{c|}{ Alternatif 3 } & \multicolumn{2}{c|}{ Kondisi Awal } & \multicolumn{2}{c|}{ Alternatif 3 } \\
\cline { 2 - 9 } & $\begin{array}{c}\text { Simpan } \\
\text { g 1 }\end{array}$ & $\begin{array}{c}\text { Simpan } \\
\text { g 2 }\end{array}$ & $\begin{array}{c}\text { Simpan } \\
\text { g 1 }\end{array}$ & $\begin{array}{c}\text { Simpan } \\
\text { g 2 }\end{array}$ & $\begin{array}{c}\text { Simpan } \\
\text { g 1 }\end{array}$ & $\begin{array}{c}\text { Simpan } \\
\text { g 2 }\end{array}$ & $\begin{array}{c}\text { Simpan } \\
\text { g 1 }\end{array}$ & $\begin{array}{c}\text { Simpan } \\
\text { g 2 }\end{array}$ \\
\hline PAGI & 1.220 & 1.016 & 0.15 & 0.93 & 46.551 & 19.792 & 5.78 & 16.16 \\
\hline SIANG & 0.888 & 0.969 & 0.30 & 0.57 & 14.974 & 17.679 & 6.80 & 9.40 \\
\hline SORE & 0.926 & 0.994 & 0.50 & 0.51 & 16.117 & 18.751 & 8.65 & 8.67 \\
\hline
\end{tabular}

\section{KESIMPULAN DAN SARAN}

Dari hasil analisis dan pembahasan yang telah dilakukan didapatkan kesimpulan sebagai berikut:

1. Pembenahan fasilitas jalan harus dilakukan seperti marka jalan, zebracross, dan rambu- rambu lalulintas agar dapat mengurangi kemacetan pada simpang tersebut.

2. Volume kendaraan yang melewati kedua simpang tersebut sangat besar pada jam sibuk yang menimbulkan kapasitas jalan pada simpang tersebut tidak bisa menampung kendaraan lagi terlihat pada hasil analisis awal simpang 3 tak bersinyal untuk kedua simpang tersebut memiliki Derajat kejenuhan sebesar $1.22 ; 1.01$ (pagi hari), $0.88 ; 0.96$ (siang hari), dan $0.92 ; 0.99$ (sore hari) kemudian untuk Tundaannya sebesar $46.5 ; 19.79$ (pagi hari), 14.97 ; 17.67 (siang hari) dan 16.11 ; 18.75 (sore hari) dengan satuan detik.

3. Pengaruh kendaraan yang berbelok dari jalan utama menuju jalan minor atau sebaliknya berdampak tundaan yang besar pada persimpangan tersebut. Geometrik pada simpang tersebut pun turut serta membuat kemacetan dikarenakan kedua simpang 3 tak bersinyal tersebut berdekatan dengan jarak 85.5 meter.

4. Analisis alternatif solusi 1 dan 2 yaitu dengan cara membuat kedua simpang tersebut simpang 3 bersinyal kemudian dikoordinasikan tidak dapat dilakukan karena nilai DS dan panjang antrian yang cukup besar. Dan pada alternatif 2 yaitu menggabungkan kedua simpang tersebut menjadi satu simpang empat bersinyal masih kurang efektif dikarenakan pada jam sibuk DS dan panjang antrian di simpang tersebut cukup besar.

5. Dari analisis ke 3 alternatif pada simpang tersebut didapatkan alternatif solusi terpilih yaitu alternatif ke 3 yang dapat menghasilkan Derajat kejenuhan yang kecil pada waktu pagi, siang dan sore dengan rata-rata DS $<0.6$ dan tundaan simpang yang kecil dengan cara memasang median jalan pada simpang tersebut sepanjang $300 \mathrm{~m}$. 
Saran yang dapat disampaikan sehubungan dengan penelitian ini adalah untuk melakukan survei volume lalulintas sebaiknya selalu menggunakan alat perekam video dan menggambil videonya pun dari ketinggian agar dapat menghasilkan hasil yang lebih akurat dan jelas karena dapat diputar berulang-ulang. Kemudian perlu dilakukan survei lebih lanjut tentang prilaku kendaraan di daerah simpang tersebut bilamana sudah dipasangnya marka jalan.

\section{DAFTAR PUSTAKA}

1. Direktorat Jenderal Bina Marga. (1987). Produk Standar Untuk Jalan Perkotaan. Direktorat Jenderal Bina Marga, Jakarta.

2. Direktorat Jenderal Bina Marga-Sweroad. (1997). Manual Kapasitas Jalan Indonesia. Direktorat Jenderal Bina Marga, Jakarta.

3. Direktorat Jenderal Bina Marga. (1992). Perencanaan Geometri Untuk Jalan Perkotaan. Direktorat Jenderal Bina Marga, Jakarta.

4. Direktorat Pembinaan Jalan Kota. (1990). Panduan Penentuan Klasifikasi Fungsi Jalan di Wilayah Perkotaan. Direktorat Jenderal Bina Marga, Jakarta.

5. Duddy S, Moch. (2004). Analisa Kapasitas Simpang Bersinyal. Jurusan Teknik Sipil Politeknik Negeri Bandung, Bandung.

6. Jananuraga, D. (2009). Peningkatan Kinerja Simpang ATCS (Area Traffic Control System ) Jalan LLRE Martadinata-Ir.H.Juanda, Kota Bandung. Politeknik Negeri Bandung, Bandung

7. Kusnandar, E. (2006). Teknik Perancangan Jalan Dan Jembatan. Departemen Pekerjaan Umum, Bandung.

8. Novianti, S. (2007). Analisis ATCS Aktivitas Lalu Lintas Wilayah Kota Bandung. Universitas Pajajaran, Bandung.

9. Desutama, R.B.P. (2008). Teknik Lalu Lintas. Jurusan Teknik Sipil Politeknik Negeri Bandung, Bandung. 